\title{
UTILITY OF PLACENTAL LEUCINE AMINOPEPTIDASE/OXYTOCINASE IN THE PREDICTION OF PRETERM DELIVERY IN PREGNANT WOMEN WITH THREATENED PRETERM LABOR
}

\author{
MIAMI ABD-AL HASSAN, ISRAA TALIB ABD AL KADIR*, NOOR HUMAM MOHAMMED \\ Department of Obstetrics and Gynaecology, College of Medicine/Al Mustansyria University, Al-Yarmouk Teaching Hospital, Baghdad/Iraq. \\ Email: israa_talib79 @yahoo.com
}

Received: 26 January 2019, Revised and Accepted: 26 March 2019

\begin{abstract}
Objective: The study objective was to assess the utility of placental leucine aminopeptidase (P-LAP) marker for the prediction of delivery in patients presented with threatened preterm labor (TPL).

This study was conducted at the Obstetrics and Gynaecology Department of Al-Yarmouk Teaching Hospital in the period from March 2017 to June 2018.

Methods: This study included 90 pregnant women with gestational age from (28-36+6) weeks; 45 of them who presented with preterm uterine contractions were considered as the study group which was further subdivided into three subgroups according to gestational age $28-31^{+6}$ weeks, $32-$ $33^{+6}$ weeks, and $34-36^{+6}$ weeks. The other 45 pregnant women who presented to the hospital for regular antenatal care visit at comparable gestational age to the study group were considered as the control group. Hence, this study aimed to assess the serum level of P-LAP in both groups and compare it between those delivered preterm from term to assess its applicability as a predictor of preterm labor.
\end{abstract}

Results: Serum level of P-LAP in pregnant women presented with TPL was found to be significantly lower in those delivered preterm (p<0.001), compared to those continued to term and control group especially in gestational ages $\geq 32$ weeks, while the study found P-LAP level to be statistically insignificant in gestational age $<32$ weeks ( $\mathrm{p}=0.052)$. The cutoff point for P-LAP serum level was $=21$ (IU/ml) that below it, the pregnant women with TPL most probably deliver before 37 weeks of gestation with Sensitivity (85.7\%) Specificity (90.3\%), Positive predictive value (80.0\%) Negative predictive (93.3\%).

Conclusion: The serum level of P-LAP was lower in women delivered preterm than those delivered at term, so it can be used as one of the markers for the prediction of preterm delivery, especially at gestational age $>32$ weeks.

Keywords: Placental leucine aminopeptidase, Pregnant women, Preterm birth.

(C) 2019 The Authors. Published by Innovare Academic Sciences Pvt Ltd. This is an open access article under the CC BY license (http://creativecommons. org/licenses/by/4. 0/) DOI: http://dx.doi.org/10.22159/ajpcr.2019.v12i4.32053

\section{INTRODUCTION}

Term pregnancy is defined as gestational age from $37^{+0}$ to $41^{+6}$ weeks, whereas preterm birth (PTB) is defined as delivery of a baby before 37 completed weeks of pregnancy [1]. The onset of labor may be diagnosed by documented uterine contractions (at least once in every $10 \mathrm{~min}$ ) and documented cervical change with an estimated cervical length of $<1 \mathrm{~cm}$ or cervical dilation of $>2 \mathrm{~cm}$. Threatened preterm labor (TPL) is diagnosed when there are documented regular uterine contractions but no evidence of cervical change $[2,3]$. The prevalence of PTB varies among different ethnic groups. Globally, 35\% of neonatal deaths are due to prematurity [4]. PTB is the single-largest cause of death among children under the age of 5 years [5]. With improvement of fertility treatment, more cases with TPL are seen due to the higher incidence of multiple gestation [6]. The pathophysiology of PTB is unknown; however, various causes including activation of the maternal/fetal (hypothalamic-pituitary axis), inflammation or infection, decidual hemorrhage, and abnormal uterine distension [7-9]. Unexplained spontaneous PTB (SPTB) is the main cause of preterm labor [10]. Nowadays, evidence of genetic factor thought to affect the duration of gestation [11]. For early detection of preterm labor, various screening tools have been used including monitoring of uterine activity, assessment of cervical length by ultrasound, cervical fetal fibronectin measurement, and the presence of bacterial vaginosis in early pregnancy $[12,13]$. Placental leucine aminopeptidase (P-LAP), which is called oxytocinase or insulin-regulated aminopeptidase, is a glycosylated aminopeptidase Type II integral membrane protein of 1024 amino acids, which belongs to $\mathrm{Zn}^{+2}$ [14]. P-LAP is mostly synthesized from placental syncytiotrophoblasts during pregnancy. It degrades several peptide hormones which are produced by the fetus such as oxytocin, vasopressin, and angiotensin II [15] Aminopeptidases are large molecules that do not cross the placental barrier; hence they act as antiuterotonic and antihypertensive agents by degrading these peptides [16]. P-LAP activity level in maternal serum increases with the gestational age to reach a maximum near term and reaching a plateau just prior to the onset of labour. P-LAP is useful for predicting the time of labor onset, especially in preterm labor $[17,18]$. Studies on oxytocinase's role in regulating blood pressure and uterine contraction during pregnancy have been carried out focusing on the possibility to use it in the treatment of preterm labor and pre-eclampsia [19-21].

\section{Aim of study}

The objective of this study is to evaluate the accuracy of serum level of P-LAP $\backslash$ oxytocinase in pregnant women who presented with TPL as a predictor of preterm delivery.

\section{METHODS}

Study design

This study was a prospective case-control study. 


\section{Setting}

This study was conducted at the Obstetrical Department of Al-Yarmouk Teaching Hospital in Baghdad city and was carried out from March 2017 to June 2018 after approval by the supervising committee of Arabic Board of Obstetrics and Gynaecology. Verbal consent was obtained from all the patients. Forty-five patients who attended our hospital for routine antenatal care visit with comparable gestational age and had no uterine contractions were included in the study and were considered as control group.

\section{Inclusion criteria}

Pregnant with Singleton alive fetus, Gestational age 28- 36+6 weeks determined by Last menstrual period and/or reliable obstetrical ultrasound at first trimester were eligible to be enrolled in the control group. For study group: Women with regular uterine contraction at least one every 10 minutes with cervical dilatation $<2 \mathrm{~cm}$ were included.

\section{Exclusion criteria}

- Diabetes mellitus

- Chronic and gestational hypertension

- Leaking of liquor (prelabor rupture of membranes)

- Chorioamnitis

- Vaginal bleeding

- Fetal distress.

Those patients who fulfilled the inclusion and exclusion criteria and agreed to participate in the study were subjected to the following:

1. Clinical history including:

- History of present illness

- Past obstetrical history (e.g., gravida, parity, history of preterm labor)

- Past gynecological history (e.g., genital infections)

- Drug history

- Pastsurgical (e.g., cervical conization)

- Social history.

2. Clinical examination including:

a. General examination which includes body mass index and vital signs.

b. Obstetrical examination: Abdominal examination by Leopold's maneuvers and speculum examination for the study group.

3. Laboratory investigations for all patients:

a. $10 \mathrm{~mL}$ of venous blood was taken from all patients and sent for the following investigations:

1. Complete blood count

2. Random blood sugar

3. Liver function tests

4. $5 \mathrm{~mL}$ of blood was collected and used for serum P-LAP level test which was allowed to clot for $2 \mathrm{~h}$ at room temperature and then centrifuged for $20 \mathrm{~min}$ at approximately $1000 \times \mathrm{g}$. The supernatant was collected and stored at $-20^{\circ} \mathrm{C}$ until the time of transport to the private laboratory where the level of P-LAP was assayed and the results were expressed as $I U \backslash \mathrm{mL}$. The lower detection limit of the assay was $5 \mathrm{IU} \backslash \mathrm{mL}$. The kit used was human (leucyl-cystinyl aminopeptidase) kit based on sandwich enzyme-linked immunosorbent assay technology, manufactured by My BioSource $\backslash$ USA.

b. Midstream general urine examination done for all patients to exclude urinary tract infection and proteinuria.

4. Management of TPL for study group patients:

Patients of the study group were admitted to the Obstetrical Department at Al-Yarmouk Teaching Hospital and were given the following tocolytic agents according to our hospital policy:

1. $\mathrm{Ca}^{++}$channel blockers: Nefidipine (Adalat) capsule $(10 \mathrm{mg}$ ) per oral as loading dose (one capsule) and then assessment of uterine contractions after $30 \mathrm{~min}$; if not subsided, the dose was repeated and then reassessment of contraction was also made after $30 \mathrm{~min}$ from the second dose if uterine contractions did not subside and one other capsule was given as the last dose. If contraction subsided, the patient was kept on maintenance dose as one capsule every $8 \mathrm{~h}$.

2. Progestational agents: Dydrogesterone (Duphaston) film-coated tablets (10 mg) per oral and progesterone (Cyclogest) $400 \mathrm{mg}$ vaginal pessaries. If contractions had not subsided and delivery proceeded, the patient had been referred to the labor room or operation theater according to obstetrical indication.

5. Follow-up:

After treatment was given to the study group, if patients' uterine contractions subsided, then the patients were hospitalized for further $48 \mathrm{~h}$, then discharged home, and further followed up till the time of delivery for risk of preterm labor. Patients in the control group also were followed up to the time of delivery for risk of preterm labor.

\section{Statistical analysis}

The data were analyzed using Statistical Package for the Social Sciences (SPSS, ver. 22, IBM-Armonk, New York, USA, 2017). The categorical data were presented by numbers and percentages. Pearson's Chi-square test was used to test the association between categorical variables. Continuous variables were presented by mean, standard deviations, and ranges. Independent t-test and analysis of variance were used to analyze the differences of continuous variables according to the study group. The validity criteria of P-LAP level in detecting preterm labor among women with premature uterine contraction were tested by receiver operating characteristic curve method. $p$ value was considered statistically significant at 0.05 level.

\section{RESULTS}

A total of 90 pregnant women (45 preterms and 45 controls) were included in the study; their age ranged from 21 to 34 years, their parity was from primigravida up to 5 parities, their gestational ages at presentation were from 28 to $36^{+6}$ weeks, control group collected at comparable gestational age $(28-36+6)$ to study group (Table 1$)$.

Fig. 1 shows pregnancy outcome in the study group as $66.6 \%$ of them were delivered term and $33.4 \%$ were delivered preterm.

As shown in Table 2, the maternal age was significantly associated with PTB ( $p=0.027)$, whereas the parity association with PTB was not significant $(\mathrm{p}=0.94)$.

As shown in Table 3, the gestational age at presentation among the study groups was not significantly associated with being term or preterm delivery $(\mathrm{p}=0.982)$, whereas the gestational age at delivery among the study groups was significantly associated with term or preterm delivery $(\mathrm{p}<0.001)$, and there was no significant association between the mode of delivery and being term or preterm $(\mathrm{P}=0.897)$.

Table 4 shows that there was no significant association between fetal gender and being delivered term or preterm $(p=0.684)$, but birth weights were significantly lower in preterm delivered babies $(\mathrm{p}<0.001)$. Apgar score at 1 minute and at 5 minutes was significantly lower in preterm delivered neonates (P-value $<0.001$ ) for Apgar score at 1 minute and (P-value 0.001 ) for 5 minute.

As shown in Table 5, there was a significant difference in serum P-LAP level among the study groups of different gestational ages at presentation between those delivered term and those delivered preterm, especially with gestational age groups $\geq 32$ weeks ( $p<0.001)$. There was no significant difference in the level of serum P-LAP $(p=0.152)$ at gestational age $\leq 32$ weeks.

Table 6 shows that the sensitivity and negative predictive value (NPV) of P-LAP to determine preterm delivery among women with TPL according to gestational age at presentation was $100 \%$.

In Fig. 2, the cut-off point for P-LAP level was $=21(\mathrm{IU} / \mathrm{mL})$ that below it the pregnant women with threatened preterm labour (TPL) most probably deliver before 37 weeks of gestation; the test sensitivity was $85.7 \%$, specificity was $90.3 \%$, positive predictive value (PPV) was 
Table 1: Demographic characteristics of the control and study groups

\begin{tabular}{|c|c|c|c|}
\hline \multirow[t]{2}{*}{ Variables } & \multirow{2}{*}{$\begin{array}{l}\text { Control group }(n=45) \\
\text { Mean } \pm \text { SD }\end{array}$} & \multirow{2}{*}{$\begin{array}{l}\text { Study group }(n=45) \\
\text { Mean } \pm \text { SD }\end{array}$} & \multirow[t]{2}{*}{ p value } \\
\hline & & & \\
\hline Maternal age (years) & $26 \pm 5$ & $31 \pm 5$ & $0.006^{*}$ \\
\hline Parity & $2 \pm 2$ & $3 \pm 2$ & 0.728 \\
\hline Gestational age at presentation (weeks) & $33.4 \pm 1.9$ & $33.3 \pm 2$ & 0.898 \\
\hline Gestational age at delivery (weeks) & $39 \pm 1.1$ & $36.4 \pm 1.6$ & $<0.001^{*}$ \\
\hline Gestational age groups at presentation (weeks) & n (\%) & n (\%) & \\
\hline $28-31^{+6}$ & $7(15.6)$ & $7(15.6)$ & 1 \\
\hline $32-33^{+6}$ & $23(51.1)$ & $23(51.1)$ & \\
\hline $34-36^{+6}$ & $15(33.3)$ & $15(33.3)$ & \\
\hline Total & $45(100)$ & $45(100)$ & \\
\hline
\end{tabular}

Table 2: Comparison of women's age and parity among the study groups with the term and preterm deliveries

\begin{tabular}{|c|c|c|c|c|}
\hline \multirow[t]{3}{*}{ Variables } & \multirow{3}{*}{$\begin{array}{l}\text { Controls, } \mathrm{n}=45 \\
\text { Mean } \pm \text { SD }\end{array}$} & \multicolumn{2}{|l|}{ Study group } & \multirow[t]{3}{*}{$p$ value } \\
\hline & & Term delivery, $n=30$ & Preterm delivery, $\mathrm{n}=15$ & \\
\hline & & Mean $\pm S D$ & Mean \pm SD & \\
\hline Maternal age & $26 \pm 5^{s}$ & $29 \pm 6$ & $32 \pm 5$ & $0.027^{*}$ \\
\hline Parity & $2 \pm 2$ & $3 \pm 2$ & $3 \pm 2$ & 0.94 \\
\hline
\end{tabular}

SD: Standard deviation, *Significant at 0.05 by ANOVA, s:Significantly different group, ANOVA: Analysis of variance

Table 3: Gestational age at presentation among the study groups with regard to term and preterm deliveries, and the association with the mode of delivery

\begin{tabular}{|c|c|c|c|c|}
\hline \multirow[t]{3}{*}{ Variables } & \multirow{3}{*}{$\begin{array}{l}\text { Controls, } \mathrm{n}=45 \\
\text { Mean } \pm \text { SD }\end{array}$} & \multicolumn{2}{|l|}{ Study group } & \multirow[t]{3}{*}{ p value } \\
\hline & & \multirow{2}{*}{$\begin{array}{l}\text { Term delivery, } \mathrm{n}=\mathbf{3 0} \\
\text { Mean } \pm \text { SD }\end{array}$} & \multirow{2}{*}{$\begin{array}{l}\text { Preterm delivery, } \mathrm{n}=15 \\
\text { Mean } \pm \text { SD }\end{array}$} & \\
\hline & & & & \\
\hline Gestational age at presentation (weeks) & $33.4 \pm 1.9$ & $33.3 \pm 1.9$ & $33.4 \pm 2.2$ & 0.982 \\
\hline Gestational age at delivery (weeks) & $39 \pm 1.1$ & $37.5 \pm 0.9^{*}$ & $36 \pm 1.3 \mathrm{~s}$ & $<0.001^{*}$ \\
\hline Groups of gestational age at presentation (weeks) & n (\%) & n (\%) & n (\%) & \\
\hline $32-33^{+6}$ & $23(51.1)$ & $16(53.3)$ & $7(46.7)$ & \\
\hline $34-36^{+6}$ & $15(33.3)$ & $9(30)$ & $6(40)$ & \\
\hline Mode of delivery & n (\%) & n (\%) & n (\%) & \\
\hline Vaginal delivery & $31(68.9)$ & $22(73.3)$ & $11(73.3)$ & 0.897 \\
\hline Cesarean section & $14(31.1)$ & $8(26.7)$ & $4(26.7)$ & \\
\hline
\end{tabular}

SD: Standard deviation, *Significant at 0.05 by ANOVA, s: significantly different group, ANOVA: Analysis of variance

Table 4: Parameters of the delivered neonates among the study and control groups

\begin{tabular}{|c|c|c|c|c|}
\hline \multirow[t]{2}{*}{ Variables } & \multirow[t]{2}{*}{ Controls, $n=45$} & \multicolumn{2}{|l|}{ Study group } & \multirow[t]{2}{*}{ p value } \\
\hline & & Term, $n=30$ & Preterm, n=15 & \\
\hline \multicolumn{5}{|l|}{ Gender of the baby } \\
\hline Female & $26(57.8)$ & $15(50)$ & $7(46.7)$ & \\
\hline Birth weight (g) & $3230 \pm 408$ & $3356 \pm 497$ & $2203 \pm 600^{s}$ & $<0.001^{*}$ \\
\hline Apgar score at $1 \mathrm{~min}$ & $7 \pm 1$ & $8 \pm 1$ & $6 \pm 1^{s}$ & $<0.001^{*}$ \\
\hline Apgar score at $5 \mathrm{~min}$ & $8 \pm 1$ & $8 \pm 1$ & $7 \pm 1^{s}$ & $0.001^{*}$ \\
\hline
\end{tabular}

SD: Standard deviation, *Significant at 0.05 by ANOVA, s: Significantly different group, ANOVA: Analysis of variance

$80.0 \%$, NPV was $93.3 \%$, and accuracy was $88.9 \%$. The dotted line in Fig. 2, represents the cutoff point for serum P-LAP level, which is equal to $21 \mathrm{IU} / \mathrm{mL}$.

\section{DISCUSSION}

PTB is a major cause of neonatal mortality, which is estimated to be at least $50 \%$ of all neonatal deaths, with the highest rates of health-care costs due to hospitalization of women with preterm labor and the expenses of long-term care of PTB [22]. preterm birth rates have increased all over world even in most industrialised countries during the past two decades, so efforts to lower the rate of this major complication of pregnancy needs to be one of the highest priorities in contemporary health care [23]. Prediction of PTB considered one of most important steps in prevention of PTB and its complications [24]. 
Table 5: Comparison of P-LAP levels among the study and control groups according to gestational age at presentation

\begin{tabular}{|c|c|c|c|c|}
\hline \multicolumn{5}{|l|}{ Serum P-LAP level $(\mathrm{IU} \backslash \mathrm{mL})$} \\
\hline \multirow[t]{2}{*}{ Gestational age at presentation (weeks) } & Controls, $n=45$ & Term, $\mathbf{n}=\mathbf{3 0}$ & Preterm, n=15 & p value \\
\hline & Mean \pm SD & Mean \pm SD & Mean \pm SD & \\
\hline $28-31^{+6}$ & $31.1 \pm 29.9$ & $25.6 \pm 23.8$ & $12.1 \pm 11.8$ & 0.152 \\
\hline $32-33^{+6}$ & $57.4 \pm 22.9$ & $51.4 \pm 24.8$ & $13.4 \pm 2.4^{\mathrm{s}}$ & $<0.001 *$ \\
\hline $34-36^{+6}$ & $79.6 \pm 16^{s}$ & $63.2 \pm 26^{s}$ & $12.3 \pm 9.2^{\mathrm{s}}$ & $<0.001^{*}$ \\
\hline Overall & $66 \pm 23.7$ & $56.7 \pm 25.5$ & $13.7 \pm 6.9^{\mathrm{s}}$ & $<0.001^{*}$ \\
\hline
\end{tabular}

SD: Standard deviation, *Significant at 0.05 by ANOVA, s: significantly different group, P-LAP: Placental leucine aminopeptidase

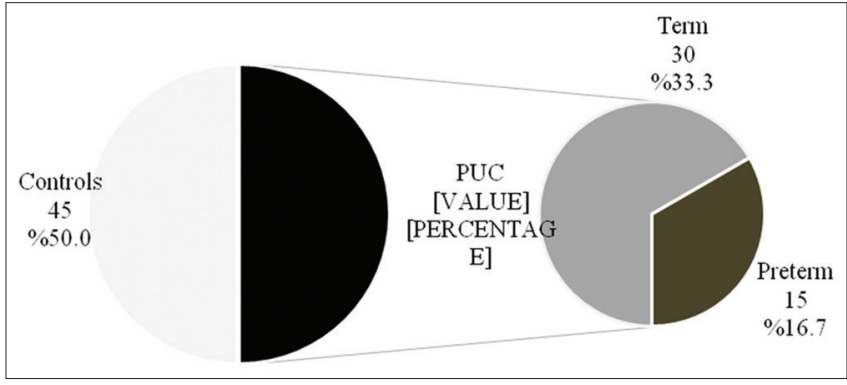

Fig. 1: Study group, $n=90$

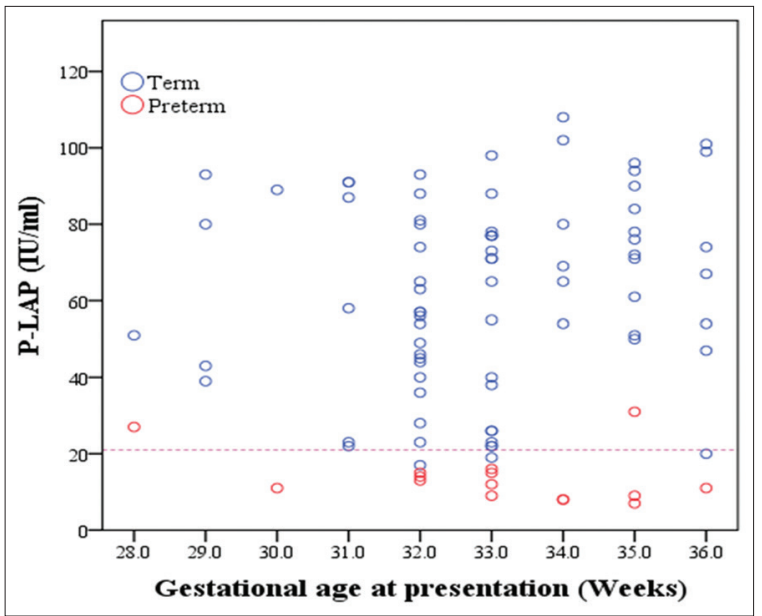

Fig. 2: Relation of placental leucine aminopeptidase level with gestational age at presentation according to outcome, $n=90$

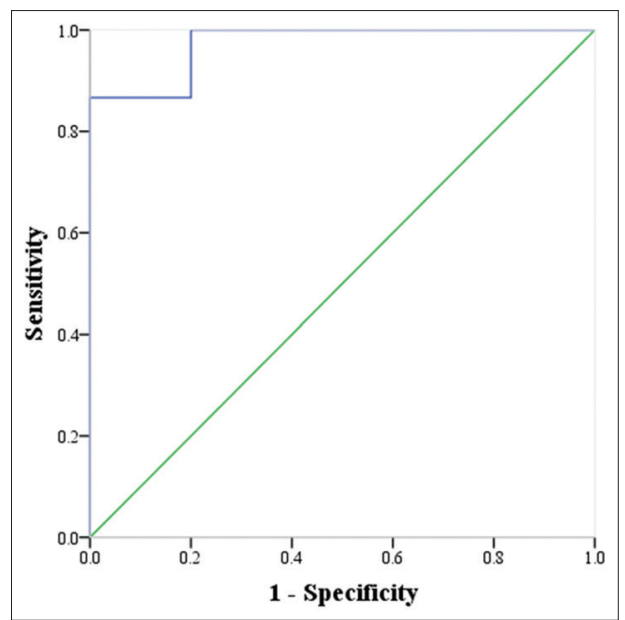

Fig. 3: Receiver operating characteristic curve for the detection of placental leucine aminopeptidase validity in the detection of preterm births among women presenting with threatened preterm labor

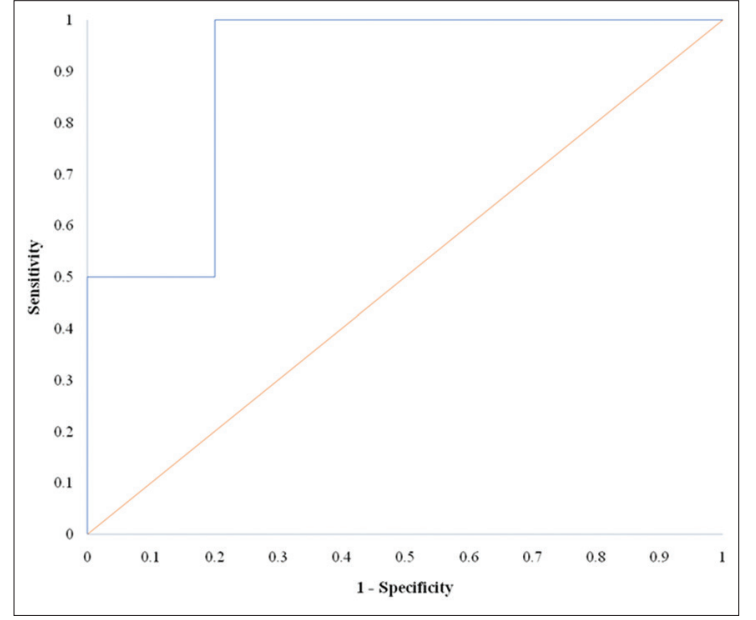

Fig. 4: Receiver operating characteristic curve for the detection of placental leucine aminopeptidase validity in the detection of preterm births among women presenting with threatened preterm labor at gestational age of $28-31^{+6}$ weeks

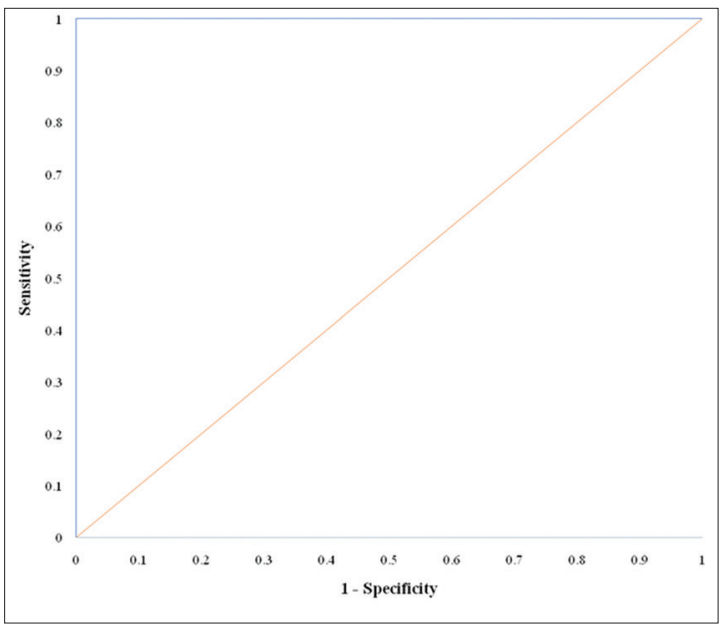

Fig. 5: Receiver operating characteristic curve for the detection of placental leucine aminopeptidase validity in the detection of preterm births among women presenting with threatened preterm labor at gestational age of $32-33^{+6}$ weeks

Numerous biochemical markers, for example, fetal fibronectin, cervical interleukin-6, and $\alpha$-fetoprotein have been investigated for the prediction of PTB, which may also explain the mechanism of SPTB [25]. In this study, we investigated P-LAP level in women presented with TPL and followed them up to the time of delivery to assess the difference in P-LAP level between those who continue till term and those who delivered preterm.

In the current study, maternal age was significantly different in preterm delivered group ( $\mathrm{p}=0.006)$. Higher incidence of preterm labor was found 
Table 6: Validity criteria of P-LAP to determine preterm delivery among women with TPL, according to gestational age at presentation

\begin{tabular}{lllllll}
\hline $\begin{array}{l}\text { Groups according to } \\
\text { gestational age (weeks) }\end{array}$ & P-LAP (IU/mL) & AUC* & Sensitivity & Specificity & PPV** & NPV $* * *$ \\
\hline $28-31^{+6}$ & 27 & 0.9 & 100.0 & 80.0 & 66.7 & 100.0 \\
$32-33^{+6} 86$ & 16 & 1 & 100.0 & 100.0 & 100.0 & 100.0 \\
$34-36^{+6}$ & 31 & 0.981 & 100.0 & 88.9 & 85.7 & 100.0 \\
\hline
\end{tabular}

*AUC: Area under curve, ${ }^{* *}$ PPV: Positive predictive value, ${ }^{* * *} \mathrm{NPV}$ : Negative predictive value, P-LAP: Placental leucine aminopeptidase, TPL: Threatened preterm labor

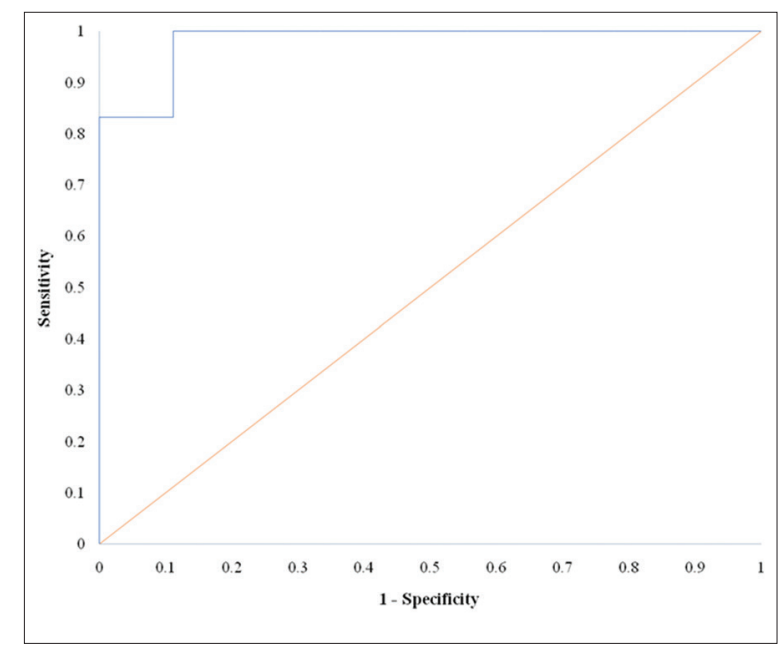

Fig. 6: Receiver operating characteristic curve for the detection of placental leucine aminopeptidase validity in the detection of preterm labor among women presenting with threatened preterm labor at gestational age of $34-36^{+6}$ weeks

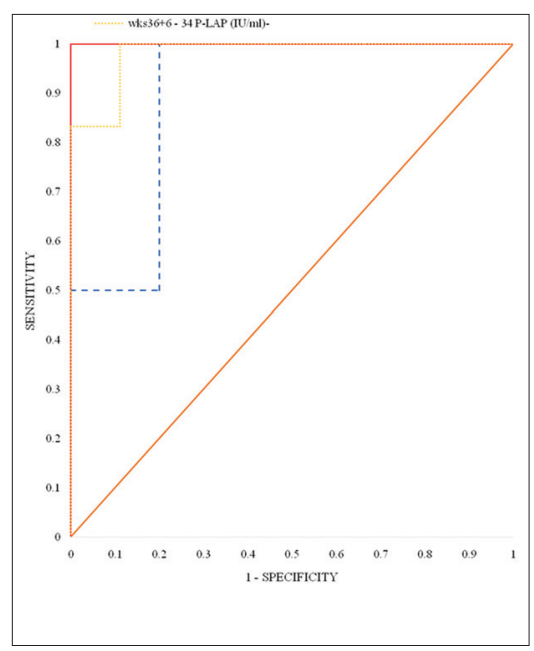

Fig. 7: Extra comparison between three groups of gestational ages included

in patients older than 31 years, a finding which is in agreement with other studies like Waldenström et al.'s study, 2016 [26]. Iin his study advance maternal age(women aged 35 years and older) was associated with an increased risk of PTB, and Florent Fuchs et al study 2018 [27], confounded that advanced maternal age ( $>40$ years old) was associated with higher risk of preterm labor. The difference in maternal age of the current study and that of others might have attributed to the social differences of our community (e.g., lower age of marriage) from that of others. While Goisis et al.'s study, 2017 [28], disagree with this finding, in which comparison between maternal ages (25-29) years with maternal ages of $(35-39)$ years and $(\geq 40)$ years were associated with percentage increases of 1.1 points (95\% confidence intervals[CI]:0.8, $1.4)$ and 2.2 points (95\% CI: $1.4,2.9)$, respectively, in the probability of PTB, while in within-family models, the relationship between advanced maternal age and low birth weight or PTB is statistically and substantively negligible. Thus, the study states that advanced maternal age is not independently associated with the risk of low birth weight or preterm delivery among mothers who have had at least two live births.

With regard to parity, in the current study, there was no significant difference between maternal parity and birth of preterm, and this was in agreement with Lisonkova et al.'s study, 2010 [29], which concluded that older women were at elevated risk of PTB and neonatal intensive care unit admission regardless of parity. The study claimed that parity modifies the effect of maternal age on the incidence of PTB, as older primiparas were at higher risk of PTB than older multiparas.

While the current study disagreed with Shaikh et al study 2011 [30] and Kozuki et al study 2013 [31]. Their studies confound that PTB was associated with nulliparous women (especially maternal age $<18$ years of age) and higher parity $\geq 3$ (especially maternal age $\geq 35$ ) mothers.

The distribution of neonatal gestational age for those who delivered preterm was predominantly among $32-33^{+6}$ weeks of gestational age, and this finding was in disagreement with that of Kuzniewicz et al.'s study, 2017 [32], which was a retrospective cohort study of singleton pregnancies that involved 365,897 pregnant women presented with TPL. Preterm delivery occurred in $85 \%$ of admitted cases within $48 \mathrm{~h}$ of admission. Nearly $96 \%$ of the delivered cases were at gestational age $\geq 34$ weeks, $67 \%$ at $31-33$ weeks, and $51.9 \%$ at $<31$ weeks. The current study results showed that $13.33 \%$ of preterm deliveries were at $28-31^{+6}$ weeks of gestation, while $46.66 \%$ were at $32-33^{+6}$ weeks and $40 \%$ at $34-36^{+6}$ weeks.

The current study showed no significant association between gender of baby and being delivered preterm, a finding which is in agreement with that of Teoh et al.'s study, 2018 [33], which was a cohort prospective study carried out on 2505 pregnant women, who were at high risk of preterm delivery, divided according to gender into two groups, and were observed till the time of delivery. The difference in the incidence of preterm delivery between female and male newborns was found to be nonsignificant with a relative risk [RR] of $1.07(p=0.383)$.

Peelen et al.'s study, 2016 [34], and Brettell et al.'s study, 2008 [35], considered male gender as a risk factor for preterm labor. Peelen et al.'s study comprised 1,736,615 singleton deliveries between 25 and $42^{+6}$ weeks of gestation, in which male gender was found to be associated with higher incidence of spontaneous preterm delivery, especially at 27-31 weeks of gestation (RR 1.5), while the incidence was equal for both genders in indicated preterm delivery. Whereas in Brettell et al.'s study, a retrospective study conducted on 75,725 deliveries in a UK teaching hospital, 4003 women were delivered preterm, male delivery was more frequent in spontaneous but not indicated preterm delivery (OR 1.30, 95\% CI 1.19-1.42).

Regarding Apgar score for newborn babies, the current study showed a significant difference $(\mathrm{p}<0.001)$ as it was lower in those delivered preterm, and this agreed with the studies of Svenvik et al., 2015 [36], and Lee et al., 2010 [37].

Svenvik et al. conducted a retrospective registry cohort study involving 21,126 births, analysis of risk factors in new-borns with Apgar Score 
$<7$ revealed preterm delivery is the most common factor, in $\left(32-36^{+6}\right)$ gestational weeks.

However, Lee et al cohort study included 690,933 live births their gestational age range $24-36^{+6}$ weeks, results were showed that Apgar score distributed according to the gestational age at delivery and higher proportions of low Apgar scores at 5 minutes found with younger gestational age. Current study showed that serum P-LAP level in pregnants who delivered preterm at $\left(32-33^{+6}\right)$ and $\left(34-36^{+6}\right)$ weeks of gestation was significantly lower than those delivered term in both the study and in control groups, P-value $(<0.001)$, this agreed with H. Kozaki et al. study 2001 [38], while in the gestational age group (28-31+6) weeks study showed non-significant difference in serum P-LAP level with p-value (0.152) and this disagree with H. Kozaki et al. study 2001.

Kozaki et al.'s [38] study assessed the maternal serum P-LAP activity in 61 women who presented with preterm labor and followed them until the time of delivery. This study was preceded by a prospective study by the same authors which involved 1536 healthy pregnant women who had no associated medical diseases and delivered at term and determined normal reference values for P-LAP activity in different gestational ages of pregnancy. Results of serum P-LAP activity in those presented with preterm labor showed that, if it was below the $10^{\text {th }}$ centile, there was a greater proportion of preterm delivery $(\mathrm{p}=0.0085)$. Moreover, the risk to deliver preterm increased to 2.3 folds. The sensitivity, specificity, PPV, and NPV were 29\%, 97\%, 89\%, and 62\%, respectively. The study concluded that maternal serum P-LAP activity decreases in cases of spontaneous preterm delivery, and can be used as a possible predicting marker for preterm labor because of its low sensitivity and hence the authors recommended to use other markers along with it, especially in cases of chorioamnitis.

In the current study, the sensitivity, specificity, PPV, NPV were $85.7 \%$, $90.3 \%, 80.0 \%$, and $93.3 \%$, respectively.

The study results showed $85.7 \%$ sensitivity of P-LAP test, so P-LAP can be used as one of the biomarkers in the prediction of PTB. The higher sensitivity found in our study compared to that by Kozaki et al.'s [38]. study might be probably due to high selective criteria for inclusion in our study.

The high specificity of P-LAP (90.3\%) proposes that there is a direct role of P-LAP \oxytocinase in the mechanism of PTB.

\section{CONCLUSION}

- P-LAP serum level was found to be lower in preterm delivered women than those delivered term, especially at gestational age group $\geq 32$ weeks.

- The study showed increased risk of PTB with advanced maternal age ( $>31$ years old), but there was no relation with the parity of mothers.

- Neonatal gender had no effect on the outcome of TPL.

\section{ACKNOWLEDGMENT}

Great thanks to our colleagues in the Obstetrical Department of Al Yarmouk Teaching Hospital for their help in collecting data and support in the execution of the study.

\section{CONFLICTS OF INTERESTS}

The authors declare no conflict of interest.

\section{REFERENCES}

1. Jones G. Late miscarriage and early birth. In: Baker PN, Kenny L, editors. Obstetrics by Ten Teachers. $19^{\text {th }}$ ed. London: Churchill Livingstone; 2011. p. 132.

2. Svigos JM, Dodd JM, Robinson JS. Threatened and actual preterm labor including mode of delivery high risk pregnancy. In: James D, Steer PJ, Weiner CP, editors. High Risk Pregnancy Management Options. $4^{\text {th }}$ ed.
Philadelphia, PA: Elsevier Saunders Health Sciences; 2011. p. 1052.

3. Roman AS. Late pregnancy complications. In: Decherney $\mathrm{AH}$, Lauren N, Laufer N, Roman AS. Current Diagnosis and Treatment Obstetrics and Gynecology. $11^{\text {th }}$ ed. United States: The McGraw-Hill Companies; 2013. p. 463.

4. Patel HV, Patel NH, Sodagar NR. Vitamin D receptor (VDR) gene polymorphism and maternal Vitamin D deficiency in Indian women with preterm birth (PTB). Asian J Pharm Clin Res 2017;10:219-23.

5. WHO. EMRO|Prematurity|New-Born Health $\mid$ Child and Adolescent Health. Available from: http://www.emro.who.int/child-adolescenthealth/newborn-health/prematurity.html. [Last cited on 2018 Jun 06].

6. Farhan FS, Hameed BH, Zghair MA. The effect of rectal progesterone on Doppler parameters of the uterine arteries for the prevention of preterm delivery in Iraqi population. Asian J Pharm Clin Res 2018;11:545-8.

7. Esplin MS, Varner MW. Genetic factors in preterm birth-the future. BJOG 2005;112 Suppl 1:97-102.

8. Simhan HN, Iams JA, Romero R. Preterm labor and birth. In: Obstetrics Normal and Problem Pregnancies E-Book. $7^{\text {th }}$ ed. Philadelphia, PA: Elsevier Health Science; 2017. p. 618.

9. Behrman RE, Butler AS. Prematurity at birth: Determinants, consequences, and geographic variation. In: Preterm Birth: Causes, Consequences and Prevention. Washington, DC: The National Academic Press; 2007. p. 772.

10. Swaggart KA, Pavlicev M, Muglia LJ. Genomics of preterm birth. Cold Spring Harb Perspect Med 2015;5:a023127.

11. Zhang G, Feenstra B, Bacelis J, Liu X, Muglia LM, Juodakis J, et al. Genetic associations with gestational duration and spontaneous preterm birth. N Engl J Med 2017;377:1156-67.

12. Bennett P. Preterm labour. In: Dewhurst J, Edmonds DK, editors. Dewhurst's Textbook of Obstetrics and Gynaecology. $8^{\text {th }}$ ed. London, UK: Wiley-Blackwell; 2012. p. 338.

13. Sullivan SA, Hoffman M, Elliott J. Preterm birth: Can we do better? Proc Obstet Gynaecol 2016;6:1-7.

14. Rasmussen TE, Pedraza-Díaz S, Hardre R, Laustsen PG, Carríon AG, Kristensen T. Structure of the human oxytocinase/insulin-regulated aminopeptidase gene and localization to chromosome 5q21. FEBS J 2000;267:2297-306

15. Rogi T, Tsujimoto M, Nakazato H, Mizutani S, Tomoda Y. Human placental leucine aminopeptidase/oxytocinase. A new member of Type II membrane-spanning zinc metallopeptidase family. J Biol Chem 1996;271:56-61.

16. Mizutani S, Wright JW, Kobayashi H. Placental leucine aminopeptidaseand aminopeptidase a-deficient mice offer insight concerning the mechanisms underlying preterm labor and preeclampsia. BioMed Res Int 2010;2011:286947.

17. Nomura S, Ito T, Yamamoto E, Sumigama S, Iwase A, Okada M, et al. Gene regulation and physiological function of placental leucine aminopeptidase/ oxytocinase during pregnancy. Biochim Biophys Acta 2005;1751:19-25.

18. Kenkel WM, Yee JR, Carter CS. Is oxytocin a maternal-foetal signalling molecule at birth? Implications for development. J Neuroendocrinol 2014;26:739-49.

19. Mizutani S, Yoshino M, Oya M. Placental and non-placental leucine aminopeptidases during normal pregnancy. Clin Biochem 1976;9:16-8.

20. Mizutani S, Hayakawa H, Akiyama H, Sakura H, Yoshino M, Oya M, et al. Simultaneous determinations of plasma oxytocin and serum placental leucine aminopeptidase (P-LAP) during late pregnancy. Clin Biochem 1982;15:141-5.

21. Matsui M, Fowler JH, Walling LL. Leucine aminopeptidases: Diversity in structure and function. Biol Chem 2006;387:1535-44.

22. McLaurin KK, Hall CB, Jackson EA, Owens OV, Mahadevia PJ. Persistence of morbidity and cost differences between late-preterm and term infants during the first year of life. Pediatrics 2009;123:653-9.

23. Lisonkova S, Sabr Y, Butler B, Joseph KS. International comparisons of preterm birth: Higher rates of late preterm birth are associated with lower rates of stillbirth and neonatal death. BJOG 2012;119:1630-9.

24. Di Renzo GC, Pacella E, Di Fabrizio L, Giardina I. Preterm birth: Risk factors, identification and management. In: Malvasi A, Tinelli A, Carlo G, Renzo D, editors. Management and Therapy of Late Pregnancy Complications. $1^{\text {st }}$ ed. Italy: Springer; 2017. p. 81

25. Honest H, Hyde CJ, Khan KS. Prediction of spontaneous preterm birth: No good test for predicting a spontaneous preterm birth. Curr Opin Obstet Gynecol 2012;24:422-33.

26. Waldenström U, Cnattingius S, Vixner L, Norman M. Advanced maternal age increases the risk of very preterm birth, irrespective of parity: A population-based register study. BJOG 2017;124:1235-44

27. Fuchs F, Monet B, Ducruet T, Chaillet N, Audibert F. Effect of maternal age on the risk of preterm birth: A large cohort study. PLoS One 
2018;13:e0191002.

28. Goisis A, Remes H, Barclay K, Martikainen P, Myrskylä M. Advanced maternal age and the risk of low birth weight and preterm delivery: A within-family analysis using Finnish population registers. Am J Epidemiol 2017;186:1219-26.

29. Lisonkova S, Janssen PA, Sheps SB, Lee SK, Dahlgren L. The effect of maternal age on adverse birth outcomes: Does parity matter? J Obstet Gynaecol Can 2010;32:541-8.

30. Shaikh K, Premji SS, Rose MS, Kazi A, Khowaja S, Tough S, et al. The association between parity, infant gender, higher level of paternal education and preterm birth in Pakistan: A cohort study. BMC Pregnancy Childbirth 2011;11:88.

31. Kozuki N, Lee AC, Silveira MF, Sania A, Vogel JP, Adair L, et al. The associations of parity and maternal age with small-for-gestational-age, preterm, and neonatal and infant mortality: A meta-analysis. BMC Public Health 2013;13:S2.

32. Kuzniewicz MW, Black L, Walsh EM, Li SX, Greenberg M. Outcomes of admissions for preterm labor. AJP Rep 2017;7:e106-13.
33. Teoh PJ, Ridout A, Seed P, Tribe RM, Shennan AH. Gender and preterm birth: Is male fetal gender a clinically important risk factor for preterm birth in high-risk women? Eur J Obstet Gynecol Reprod Biol 2018;225:155-9.

34. Peelen MJ, Kazemier BM, Ravelli AC, De Groot CJ, Van Der Post JA, Mol BW, et al. Impact of fetal gender on the risk of preterm birth, a national cohort study. Acta Obstet Gynecol Scand 2016;95:1034-41.

35. Brettell R, Yeh PS, Impey LW. Examination of the association between male gender and preterm delivery. Eur J Obstet Gynecol Reprod Biol 2008;141:123-6.

36. Svenvik M, Brudin L, Blomberg M. Preterm birth: A prominent risk factor for low Apgar scores. BioMed Res Int 2015;2015:978079.

37. Lee HC, Subeh M, Gould JB. Low Apgar score and mortality in extremely preterm neonates born in the United States. Acta Paediatr 2010;99:1785-9

38. Kozaki H, Itakura A, Okamura M, Ohno Y, Wakai K, Mizutani S, et al. Maternal serum placental leucine aminopeptidase (P-LAP)/oxytocinase and preterm delivery. Int J Gynaecol Obstet 2001;73:207-13. 